\title{
Refugees and immigrants in Africa: Where is an African Ubuntu?
}

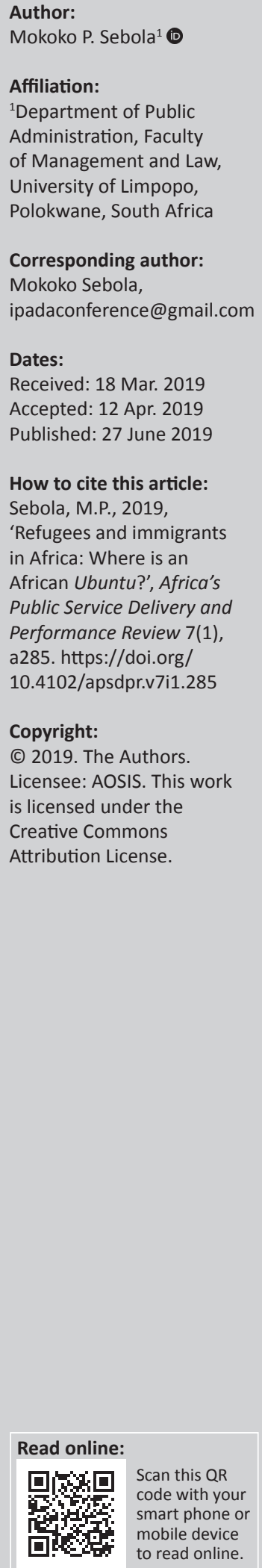

Background: International conventions set principles and standards by which immigrants have to be treated in receiving countries. A general perception held is that Africans are hostile towards each other, while those in developed countries are arguably said to be welcoming to immigrants. Although the manner in which immigrants have to be treated is influenced by the Western practices, Africans adopt approaches that cannot be defined as better in terms of African values.

Aim: The article investigates the unfair treatment of African immigrants in own continent because of ignoring the Ubuntu philosophy that guides the African life view.

Setting: The article is located within the African continent and context. It argues that the immigration policies of some African countries reflect the life views that are slightly in contradiction of the Ubuntu philosophy which underpins the African life view.

Methods: A desktop research approach was used to collect narrative materials to argue that Africans need to adopt an Ubuntu philosophy in dealing with immigrants so as to achieve their known peaceful and welcoming society.

Results: From the literature perspective, it becomes apparent that very few countries in Africa adopted immigration policies that are congruent with the Ubuntu philosophy. Immigrants from Africa are not treated with the Ubuntu approach deserved for humanity. A number of African countries with small populations experience little immigrants' problems as compared to those with larger populations.

Conclusion: This article concludes that the best approach to immigrants is the approach in which immigrants are integrated into the society rather than being put in refugee camps, which isolate them from the society.

Keywords: Afrocentric; euro-centric; humanity; immigrants; refugee.

\section{Introduction}

The belief held in modern discourses is that Africans are hostile towards each other when it comes to migration of individuals of foreign descendants in their countries. Unlike other countries in the continent, South Africa had been branded as the worst xenophobic country in Africa because of what transpired in the periods 1998, 2008 and 2014 (Madue 2015; Sebola 2017), which is an image that does not reflect their Ubuntu brand. International conventions that are mostly influenced by perspectives of the West, which appeal for human treatment of foreign nationals in times of either political or economic crisis in countries of such victims, haves been either ratified or signed by African countries (D'Orsie 2011). The fair treatment goes far beyond the political and economic refugees to skilled refugees in which definitional contestations on classifications of immigrants become visible, especially between migrants and refugees.

Such definitional contexts become irrelevant in Africa because countries in Africa are by natural orientation not to differentiate a migrant worker from a refugee because the African approach to such matter has always been to integrate both immigrants to the community than to separate them on the basis of papers. In this article, it is argued that the African approach of viewing an immigrant as a member of the community is the most protective and human than the Euro-centric approach which separates immigrants in terms of the official documentations (putting others in refugee camps). The purpose of this article is therefore to argue that Africa needs the integration of the Ubuntu principles into their immigration policies so that they become a welcoming society that was known before colonialism. African communities irrespective of geographical direction have always been used to saying like Moeng e tla ka gesu re je ka wena [a foreigner to come into our household to share food with us] and Molato o rerwa ke mofeti wa tsela [a passer-by can judge our 
local case objectively better than the internals]. Based on these two foundations in which Africans regard an outsider, an outsider was never an enemy but a person the society integrates at first glance. This article focuses its attention on the Afrocentric approach to immigrants (Ubuntu), Immigrants and Refugees, the African Policies on Immigration and to analyse the extent to which Ubuntu prevails in African protection of immigrants and refugees.

\section{The Afrocentric approach to immigrants and refugees (Ubuntu)}

The argument of this article is grounded in the African philosophy of Ubuntu. Although there is a general criticism of the Ubuntu philosophy as a general principle that can be applicable across all African societies, mainly because of its Nguni popularity, the philosophy has been a guiding principle of an African government system across the continent. Some references argue the concept to be having relevance to the East and Southern African countries only where relationships of such words are clearly traceable, such as Ubuntu (Nguni, South Africa), Botho (Sotho Languages, South Africa), Hunhu (Shona language, Zimbabwe), Umundu or Umuntu (Kikuyu and Kimeru language, Kenya), Bumuntu (KiSukuma and kiHaya language, Tanzania), Vumuntu (TshiTsonga language, Mozambique) and Bomoto and Gimuntu (Bobangi, KiKongo and giKwese language, Democratic Republic of Congo [DRC]).

The oneness of Africa in terms of culture and political identity was shared many years ago by Kwame Nkrumah when he maintained that:

Africa is one continent, one people, and one nation. The notion that in order to have a nation it is necessary for there to be a common language, a common territory and common culture has failed to stand the test of time or the scrutiny of scientific definition of objective reality... The community of economic life is the major feature within a nation, and it is the economy which holds together the people living in a territory (United Souls, 2017:1)

It is on this basis that the new Africans recognise themselves as potentially one nation, whose dominion is the entire African continent.

Kwame Nkrumah is one of the few and first post-colonial African leaders who have believed in African Union and the oneness of Africa in the early years of African post-colonial democracy. Politicians and modern academics still make too much reference to him in terms of how African unity can be achieved. Even though during his time, he made no attempt of conceptualising the African Ubuntu philosophy. He remains a source due to his assertion that Africans, despite where the come from in the continent, share the same practices, history, approaches and experiences. Ubuntu philosophy although made famous by the South African government as a philosophy believed to be capable of healing and creating a United South African society, but 'it generally stems from, and deeply rooted in, African indigenous culture' (Gade 2012).

Madue (2015) also noted that South Africa's approach to the global issues is deeply embedded in the concept of Ubuntu. Although the concept itself is controversial and has different meanings to different people, Idoniboye-Obu and Wheto (2013:229) mentioned that the concept is 'a basis of an African Communal life which underpins an African political, business, corporate governance, justice and conflict resolution mechanism'. The concept preferably approaches any human being irrespective of his or her colour, status, ideology or origin at first as a human being. The Ubuntu philosophy puts emphasis on a human being as a being that should be treated with humanity and dignity in all matters. In the African context, the lack of or absence of Ubuntu 'may culminates [sic] into disorderly and crime-riddled societies' (Johnson \& Quan-Baffour 2016:7). While Africa has the best philosophical approach in use, for some strange reasons, this approach is ignored in Western literature even if the African governments can effect such practice in their constitutions. Nussbaum (2003:1-2) argues that African values have the potential to play a leading world consciousness, but are inaccessible to the global community because of the following:

- They are not communicated through formal medium such as books and journals.

- Some political leaders betray their own values and principles which ultimately fail them and the Westerners view them negatively.

- People from the West are only fed with the negatives such as wars, dictatorship, famine and AIDS.

The impact of all the above is nothing other than the West prescribing for solutions in Africa that are more controversial than problems already experienced in African governments. It is indeed very clear that the international conventions on immigrants and refugees prescribed are not all synchronous with how the African society views an immigrant. Africans are indeed not making noise about it handling the immigrants through an African Ubuntu philosophy as opposed to the Westerners who prescribe a protection that is not clearly embedded in the notion of safeguarding humanity of individuals as claimed.

\section{Immigrants and refugees in African context}

The pattern of migration in Africa seems to have changed in the past few decades. African countries had in the past decades welcomed immigrants from neighbouring countries with warm hands as they viewed them then as victims of colonisation (Maple 2016:11). It may seem that not only the perception has changed about who an African immigrant is, but also African countries seem to have lost the purpose of migration of fellows in the continent. It may seem African leaders then warmly welcomed individuals because they were running away from the system they hated which was perpetuated by colonial masters. Indeed, many countries 
accepted that the open-door policy for immigrants in the 1960s did not help their countries to grow better but instead created problems. The worst case with migration today is that countries receive mostly irregular immigrants or refugees than Critical Skills List immigrants. Critical Skills List immigrants are those that most countries today are willing to have, but instead such people come in slow numbers. The Department of Home Affairs (2016:4) defines irregular immigrants as:

Those people who enter a country, usually in search of incomegenerating activities, without the necessary documents and permits; or who stay beyond the permitted period or acquire fraudulent documents and a Refugee as a person who...

... because of a well-founded fear of persecution for reasons of race, religion, nationality, membership of a particular social group or political opinion, is outside the country of his nationality and is unable or, because of such fear, is unwilling to avail himself the protection of that country. D'Orsie (2011:85), however, noted that irregular is complex as an immigrant can become irregular in many ways. The manner in which the African leaders viewed African immigrants and refugees has indeed now changed. To a particular, extent even if Africans would have been able to adopt immigration and refugee policies that are founded on the basis of the Ubuntu, but the environmental material in which they lead politically changes their attitudes and stand on refugees.

\section{African immigration and refugee protection policies}

Migrations are common among human societies (Singh \& Khan 2017) although reasons and the manner in which immigrants were handled in the past differ from the way modern society handles migrants. Historically, societies including the South African society argue that immigrants have always been welcomed with warm hands in Africa irrespective of where they originated from. Some will argue that even colonisers of European origin were welcomed warmly and the conflict only started when they openly suggested to reduce natives into their servants and wanting to take their land by force. The problem therefore today with regard to migration may relate to the manner in which policies crafted by Africans are not highly influential as expected. Mostly problematic is the extent at which African policies on migration get expressions from the international organisations which are highly influenced by Western viewpoints. It is argued that the African Union has indeed adopted two important policy documents for migration: the African Position on Migration and Development (also called African Common Position) and the Migration Policy Framework for Africa (MPFA), which incorporate principles of migration from the international law perspective. The adoption of the MPFA in 2006 by the Organisation of African Unity (OAU) for all its member countries, as a non-binding framework, serves as a guiding document to assist governments and regional economic communities to formulate national and regional migration policies. There are indeed three migratory routes in Africa as provided by Mudungwe (2016):

- Northern route through Sudan, Libya and Egypt to Europe

- Eastern route through Djibouti, Northern Somalia, Yemen, Saudi Arabia and Middle East

- Southern route through Kenya, Tanzania, Mozambique, Zambia, Zimbabwe and Malawi to South Africa.

Like all other continents, Africa experiences both internal and external migration (from inside and outside the continent). Eighty per cent of migration is within the continent itself, which is mostly either from West to Southern or East to Southern region (Abebe 2018:4; African Union 2006:3). Currently, it is clear that the Southern region of Africa is a recipient of overall migrants from Africa. Organisationally, the OAU had long adopted the African charter which compels African countries to protect the rights of refugees in their country (Zard, Beyani \& Odinkalu 2003:33-34). From the beginning and influenced by the philosophy of African Ubuntu, the OAU prescribed that 'the grant of asylum to refugees is a peaceful and humanitarian act and shall not be regarded as an unfriendly act by any member state' (OAU 1969:3). The adherence to the philosophy of Ubuntu may also mean that countries do not have to encamp refugees as such does not really demonstrate a humanitarian acceptance of a refugee into the society. African countries going for encampment of refugees claim to do so solely on the basis of security and better than that doing it as an attempt to reduce conflict between the locals and refugees and avoiding a perceived threat in which refugees engage in criminal activities when integrated with locals (Maple 2016:11-12).

Such assertions adopted by African countries, which are not clearly in line with their philosophical upbringing, may only be accepted if they are genuinely applied. Countries such as Lesotho, Swaziland, Malawi and Tanzania are said to be having refugee acts that fairly limit the rights of refugees in the country. Of course, Botswana took exceptions on both United Nations (UN) and OAU refugees' conventions and protocols because of their previous experiences with the apartheid South African government in which instance they adopted a motion to encamp and limit the rights of refugees in the Botswana territory. The African Union (AU) Migration Policy Framework recognises such limitations, but appeals for countries to strike a balance between rights and internal security of their own citizens (Achiume \& Landau 2015).

\section{South Africa}

South Africa is believed to be the most prominent immigrant receiving country in the region (Sebola 2008, 2017) and with a substantial number of immigrants from Europe. Clearly, South African influx of immigrants increased after 1994 when South Africa inactivated the Aliens Control Act of 1991 which was mainly discriminative of specific categories of immigrants from India, Jews from Europe and Africans from Zambia, Kenya and Zimbabwe and other areas of Africa (Department of Home Affairs 2016:7). Moreover, South Africa enjoy the status of one of the most successful economies in 
the region and therefore attracts a very good flow of immigrants from the entire African continent (Tevera 2013).

The white minority South African government then fears for overpopulating the country with many black people who would politically threaten their future political existence. Numerous legislative frameworks in this regard have been implemented, namely the White Paper on International Immigration (1998), Refuges Act (1998) and Comprehensive Immigration Act (2002). South Africa adheres to both the UN 1951 Convention and the OAU Convention in dealing with refugee matters. Refugee status is temporary in nature and the 1951 Convention states that:

He [the refugee] can no longer, because the circumstances in connection with which he has been recognised as a refugee ceased to exist, continue to refuse to avail himself of the protection of the country of his nationality; Provided that this paragraph shall not apply to a refugee falling under section A (1) of this Article who is able to invoke compelling reasons arising out of previous persecution for refusing to avail himself of the protection of the country of nationality (Johnson 2012:5).

The South African task team responsible for refugee act in this instance emphasised that any final settlement on the cessation status of a refugee should essentially be concluded in a humanitarian way (Johnson 2012:7), and moreover, a refugee whose status have ceased and have been in the country for 5 years can apply for permanent residence and will be exempted pre-emptively from any cessation process that may occur in future irrespective of the results of their permanent residence status. It is clear that the UN 1951 Convention requires that a refugee should be safe in a host country and be accorded some rights such as freedom, basic needs for survival such as food, shelter and medical assistance, as well as livelihood, education and healthcare (Feller 2001). Slightly differing with other countries in the continent such as Malawi, Botswana, Tanzania, Zimbabwe, Lesotho, Swaziland, Mozambique, Namibia, Angola, Madagascar, Mauritius and Swaziland, the South African Refugee Act 130 of 1998 makes provision for the rights of refugees, which may include, and not limited to, freedom of movement in the host country, access to self-employment, education, finding own shelter and access to land ownership. Makhema (2009:12) indicated that the South African framework for refugee protection is mainly 'based on urban self - settlement with extensive socio-economic rights for asylum seekers and refugees, including the right to work'.

\section{Botswana}

Although small in population and popularity, Botswana hosted refugees from various neighbour countries in the region before they become politically independent. MachariaMokobi and Pfumorodze (2013) cited Campell as having described Botswana as a 'Country of migration'. Such attraction also emanated from the unique political stability enjoyed by the country in comparison to other sub-Saharan African countries (Oucho \& Ama 2009). Such included refugees from South Africa, Zimbabwe, Lesotho, Angola and
Namibia. South African refugees were a risk to the security of Botswana government to an extent that the country had to change its refugee approach of letting refugees stay among the civilians and to place them in the Dukwe refugee camp. A move which was not clearly helpful for safety and security of refugees because the South African government was by then not bound by the OAU declarations as the country was not a member. The Botswana government is not only accepting refugees and providing humanitarian assistance, but also has taken a reservation stand on keeping refugees among the citizenship. This is mainly because of the nasty experience they had in which refugees had previously put the safety of their citizens at risk (Macharia-Mokobi \& Pfumorodze 2013). Until today, it is believed that the Botswana government had slightly moved from the Ubuntu philosophy by choosing to encamp refugees, which is the model that is preferred by countries of European origin. While the UN 1951 and the OAU conventions mainly require the protection of refugees, the Botswana approach is seemingly controlling than protecting refugees. The feeling of Zimbabwean immigrants about the Government of Botswana is similar to that of South Africa as the country in which they have a feeling that the country is very xenophobic and do not treat the immigrants in a humanly manner (Campbell \& Crush 2012:19-25). In general, the Botswana refugee protection system is arguable one of the best because despite its encamped refugee approach, it also encourages voluntary repatriation and ad hoc option for permanent citizenship (Makhema 2009:10).

\section{Namibia}

Like South Africa and other countries looking at refugee status from an Ubuntu perspective, the Namibian refugee laws protect and integrate refugees into the local communities as per cabinet approval of 2009, which, of course, is limited by the countries reservation of Article 26 of 1951 Refugee Convention (The UN Refugee Agency 2010:3). Although the Namibian government provides free primary and secondary education and access to free medical care to refugees like the locals, they are still reluctant to allow them free movement and residence. A large group of the Namibian refugees are kept at the Osire camp (Makhema 2009:12). It is indeed not known why the Namibian government does not freely adhere Article 26 of the UN Convention on Refugees.

\section{Lesotho, Angola, Madagascar and Mauritius}

These are largely small countries in Africa, with little refugee problems. Lesotho was only significant in the last decade for harbouring refugees of South African descendants who fled from apartheid in transit to other countries. The countries do not have significant refugee policies because they are not largely affected as other countries in the continent. The United Nations High Commission for Refugees (UNHCR) administers some small-scale refugee programmes in such countries. In such countries, it is insignificant to determine whether refugees are handled in the best humanitarian approach expected by the UN Convention of Refugees and the OAU Charter as well as the AU refugee policy frameworks. 


\section{Tanzania, Malawi and Mozambique}

Although receiving refugees from different countries, the three countries have a common refugee protection approach. They all prefer to keep refugees in camps and do not allow them freedom of movements and rights to employment. It is indeed difficult to understand the countries' reason for what can be seen as an inhuman approach to refugees of African descent. It is very clear and expected that notwithstanding the challenges experienced before and now, African countries may be expected to demonstrate a certain level of humanity in dealing with refugees.

\section{Zambia}

Zambia has a history of harbouring refugees from many African countries. According to Makhema (2009:13), Zambia has practised an open reception policy for many years. Like the Government of Botswana maybe based on unpopular experience, it has enacted more restrictive refugee legislation. The government prescribed for refugees to be camped in the rural areas of its western and northern region, and refugees are restricted from obtaining permanent resident status. Local integration is still negotiated by the UN for refugees who had stayed in the community before the country adopted a restrictive refugee policy.

\section{Democratic Republic of Congo}

The DRC because of the civil wars, which even today have not completely been halted, produces both inflows and outflows of refugees, which predominantly are of Angolan origin. In the DRC Refugee Law of 2002, read with the DRC 2006 Constitution, the country provides extensive rights for refugees and foreigners (Makhema 2009:11). Such rights include freedom of movement and local integration.

\section{Is Ubuntu achievable in African migration policies?}

For countries not betraying their natural life view, Ubuntu can be factored to the migration policies to protect refugees and immigrants in an acceptable African way. Of the 13 listed countries in Africa in this article (Botswana, Namibia, Lesotho, Swaziland, Zambia, Tanzania, Malawi, Kenya, DRC, Angola, Madagascar, Mauritius and Swaziland), the majority of them indeed shift a wide away from the African Ubuntu philosophy, while others because of their small fraction intake and their problems do not have either refugee issues or migration problems. Indeed, some countries such as Zimbabwe are a burden to other countries because of economic problems and therefore cannot in anyway have a significant refugee debate on it except when it comes to its inhabitants who are outside the country. There are indeed very few African individuals that would take refuge in Zimbabwe. Little politically influential countries, such as Lesotho, Angola, Madagascar, Mauritius and Swaziland, would have little refugee problems in the country, especially after the 1990s. Contrary to African countries, the UN Convention on Refugees which as Africans we may believe it should be Western ideals influenced, prescribed articles to integrate the refugees into local communities, access to education, employment and free movement several countries reserved their sovereignty in such determination. It is just very ironical that of the 13 listed African countries in this article, only two seem to deal with refugees and immigrants in a manner that befits the Ubuntu approach towards immigrants. Only South Africa and the DRC have considerably fair refugee laws that are not only protective, but also characteristics of such countries as sufficiently considerate on humanity of the African society in diaspora. Like South Africa, the DRC allows refugees to access healthcare services, education and the rights to work as nationals (Carciotto \& d'Orsie 2017:25-26). Further to the number of African countries such as Sudan, Nigeria, Kenya and Ethiopia, the rights of refugees and immigrants remain relatively limited in terms of access to education, health and work opportunity. It is not clearly known why the DRC is so generous of refugees and immigrants despite its own domestic political problems.

South Africa's courtesy of Ubuntu may be traced to the payback time theory in which some refugees openly suggested that South Africa owes them of the time they stayed in their country during the apartheid regime (Sebola 2017). Indeed, the South African current political incumbents were in Botswana, Lesotho, Swaziland, Tanzania, Zambia, Zimbabwe and all other countries of the East and Southern Africa during their fight against the apartheid regime. Other sources, however, argue that although South African refugee laws are progressive, refugees do not completely access all benefits as allowed in South African laws (Amit \& Kriger 2014:280). As some may argue, limited rights of refugees are indeed humanitarian; however, such rights mainly result in anti-immigrant attitude by locals (Tevera 2013). There are indeed wins and losses on both sides of the humanitarian approach and the opposite ones. Generally, several African countries compromised to adopt an Ubuntu approach to their refugee laws probably for fear of security of locals and hostility which might emanate from locals and immigrants fighting over access to local resources (Madue 2015; Maharaj 2001).

The Botswana approach to refugee laws is not only fully compliant to the humanitarian Ubuntu philosophy, but also has similar characteristics of an African country where humanity is viewed on a serious light. Although the country makes several reservations of UN Articles for promoting humanitarian approach to refugees (Macharia-Mokobi \& Pfumorodze 2013), the country allows refugees to own property (Makhema 2009:31). Its ability to adopt a humanitarian approach to refugees is even surprising because unlike other countries in the continent, Batswana had hardly ever taken refuge to foreign countries. They have been a relatively peaceful country surrounded by countries of political turmoil. Indeed, its humanitarian approach to refugees of African origin should be commended. It is also commendable to understand that from the start, the Botswana government allowed refugees freedom of movement and 
access to other benefits until such time a security threat of their citizens and country became at risk. The case of the DRC is not unfamiliar to a South African case. The current Congolese politicians and bureaucrats had spent most of their time as refugees in neighbouring countries. As such their humanitarian approach may not be unexpected to their neighbours. That may also not be a true reason of such as the Namibian politicians and bureaucrats have also during their time took refuge in neighbouring countries; however, they have now adopted a tough stand against refugees and immigrants. While the adoption of the Ubuntu philosophy towards refugees and immigrants carries a substantial risk to receiving countries, a need arises to ensure that African countries reflect the Ubuntu approach in reception of immigrants and refugees within their geographical territories.

As Chawane (2016:79) rightly pointed out, Africans need to adopt 'a thought and action in which African interests, values and perspectives predominate'. Irrespective of challenges forecasted, the adoption of an African perspective in dealing with refugees and immigrants might help in reducing the level of negativity that prevails among locals and refugees. Significantly, it is notable that Africans need to understand the Ubuntu philosophy to refer to a human being characterised by being 'caring, humble, thoughtful, considerate, understanding, wise, generous, hospitable, socially mature, socially sensitive, virtuous and blessed' (Venter 2004:150). The Ubuntu, being an original African life view, can easily be adopted by African governments on that basis. Africans are indeed known throughout the world for their unique character of being nonindividualistic in nature (Lutz 2009:1-7). The Ubuntu character needs to pre-dominate the approach towards treatment of immigrants and refugees in Africa. As much as South Africa and the DRC successfully reflected such in their refugee laws, so can all other countries adopt the same Ubuntu.

\section{Conclusion}

This article evaluated one of the most critical areas of African problems. The treatment of refugees and immigrants in receiving countries has gained much attention in numerous academic literatures. This article has argued that the manner in which African countries seem to have neglected the African life view (Ubuntu) makes them fail to treat their African fellows with the dignity they deserve. While Africans have a life view based on Ubuntu, one would not have expected them to take a refugee standpoint that contradicts such a life view. This article concludes that the best approach to immigrants and refugee is the African approach in which immigrants are integrated into the society and should be given access and rights as local citizens rather than being put in refugee camps, which isolate them from the countries' membership status. Such isolation removes of them the social and economic responsibility of the receiving country, which ultimately may increase their criminal potential in the receiving country. The Ubuntu courtesy should be a two-way process: from both the receiver and the recipient. As much as immigrants receiving countries should treat immigrants with the humanity they deserve, so should the immigrants behave in the possible humanity expected from them.

\section{Acknowledgements Competing interests}

The author declares that he has no financial or personal relationships that may have inappropriately influenced him in writing this article.

\section{Author contributions}

I declare that I am the sole author of this research article.

\section{Funding}

This research received no specific grant from any funding agency in the public, commercial or not-for-profit sectors.

\section{Data availability statement}

Data sharing is not applicable to this article as no new data were created or analysed in this study.

\section{Disclaimer}

The views and opinions expressed in this article are those of the author and do not necessarily reflect the official policy or position of any affiliated agency of the author.

\section{References}

Abebe, T.T., 2018, Global compact for migration enhancing African migration governance, Policy brief 120, vol. 120, Institute for Security Studies, Pretoria.

Achiume, E.T. \& Landau, L.B., 2015, The African Union migration and regiona integration framework, African Centre for the Constructive Resolution of Disputes, Umhlanga Rocks.

African Union, 2006, 'African common position on migration and development', Executive Council Ninth Ordinary Session, Banjul, The Gambia, 25-29 June, 2006.

Amit, R. \& Kriger, N., 2014, "Making migrants "Il-legible": The policies and practices of documentation in post-apartheid South Africa', Kronos 40(1), 269-290.

Campbell, E. \& Crush, J., 2012, Unfriendly neighbours: Contemporary migration from Zimbabwe to Botswana, Southern African Migration Programme, Cape Town.

Carciotto, S. \& d'Orsie, C., 2017, Access to socio-economic rights for refugees: A comparison across six countries, The Scalabrini institute for human mobility in Africa, Cape Town.

Chawane, M., 2016, 'The development of Afrocentricity: A historical survey', Yesterday and Today 16(December), 78-99. https://doi.org/10.17159/22230386/2016/n16a5

Department of Home Affairs, 2016, Towards a White Paper on International migration in South Africa, Government Printer, Pretoria.

D'Orsie, C., 2011, 'Which legal protection for migrants sub-Saharan Africa?' New Zealand Journal of Public and International Law 9(1), 83-117.

Feller, E., 2001, 'International refugee protection 50 years on: The protection challenges of the past, present and future', International Review of the Red Cross 83(843), 581-605.

Gade, B.N., 2012, 'What is Ubuntu? Different interpretations among South Africans of descent', South Africa Journal of Philosophy 13(3), 485-501. https://doi.org/10. 1080/02580136.2012.10751789

Idoniboye-Obu, S. \& Wheto, A., 2013, “Ubuntu: "You are because I am" or "I am because you are", Alternation 20(1), 229-247.

Johnson, C.R., 2012, Ceased circumstances and the end of refugee status: The Use of Article 1C(5) in South Africa, Scalabrini Centre of Cape Town, Cape Town.

Johnson, L.R. \& Quan-Baffour, K.P., 2016, 'The African philosophy of "Ubuntu" and correctional education in South Africa: A Case study', Proceedings of the 38th AFSAAP conference: 21st century tensions and transformation in Africa, Deakin University, Victoria, October 28-30, 2015.

Macharia-Mokobi, E. \& Pfumorodze, J., 2013, 'Advancing refugee protection in Botswana through improved refugee status determination', African Human Rights Law Journal 13(1), 152-177. 
Madue, S.M., 2015, 'South Africa's foreign and migration policies missteps: Fuels of xenophobic eruptions', The Journal of Transdisciplinary Research in Southern Africa 11(4), 60-70. https://doi.org/10.4102/td.v11i4.42

Maharaj, B., 2001, 'Economic refugees in post-apartheid South Africa - Assets or liabilities?', GeoJournal 55, 47-56. https://doi.org/10.1023/A:1021756902951

Makhema, M., 2009, Social protection for refugees and asylum seekers in Southern Africa (SADC), World Bank, Washington, DC.

Maple, N., 2016, Rights at risk: A thematic investigation into how states restrict the freedom of movement of refugees on the African continent. New issues in refugee research, Research paper no. 281, The UN Refugee Agency, Geneva.

Mudungwe, P., 2016, Evaluation of the migration policy framework for Africa evaluation of the African union, The African Migration and Development Policy Centre.

Lutz, D.W., 2009, African Ubuntu philosophy and the philosophy of global management, The Catholic University of Eastern Africa, Nairobi.

Nussbaum, B., 2003, 'African culture and Ubuntu', Perspectives 17(1), 1-12.

Oucho, J.O. \& Ama, N.O., 2009, 'Immigrants and refugees 'unmet reproductive health demands in Botswana: Perceptions of public healthcare providers', South African Family Practice 51(3), 237-242. https://doi.org/10.1080/20786204.2009.10873854

Organisation of African Unity (OAU), 1969, 'OAU convention governing the specific aspects of refugee problems in Africa ("OAU Convention")', Organization of African Unity (OAU), Addis Ababa.
Sebola, M., 2008, 'Managing the provision of low cost housing in South Africa: Evaluating the access to habitable housing and the migration impact on housing delivery', Paper published in the Peer reviewed SAAPAM-G chapter conference proceedings, pp. 101-114, held at North West University, Vaal Triangle Campus, on 08 May 2008, South African Association of Public Administration and Management, 08 May 200

Sebola, M.P., 2017, 'Xenophobic attitudes against immigrants and cheap political talks: Sitting time bombs and explosives', Bangladesh e-Journal of Sociology 14(1) 89-103.

Singh, B. \& Khan, S., 2017, 'Migration dynamics in Western and Southern Africa: An introductory article', Nordic Journal of African Studies 26(2), 79-87.

South African Refugee Act 130 of 1998, 1998, Government printer, Pretoria.

Tevera, D., 2013, 'African migrants, xenophobia and urban violence in post-apartheid South Africa', Alternation 7(2013), 9-26.

The UN Refugee Agency, 2010, Submission by the United Nations High Commissione for refugees for the office of high commissioner for human rights compilation report-Universal periodic review: Namibia, United Nations, New York.

Venter, E., 2004, 'The notion of Ubuntu and communalism in African educational discourse', Studies in Philosophy and Education 23, 149-160. https://doi.org/ 10.1023/B:SPED.0000024428.29295.03

Zard, M., Beyani, C. \& Odinkalu, A., 2003, 'Refugees and the African commission on human rights and peoples' rights', Forced Migration Review 16(January), 33-35. 